\title{
Acute effects of removing large fish from a near-pristine coral reef
}

\author{
Douglas J. McCauley $\cdot$ Fiorenza Micheli $\cdot$ Hillary S. Young $\cdot$ Derek P. Tittensor • \\ Daniel R. Brumbaugh · Elizabeth M. P. Madin · Katherine E. Holmes · \\ Jennifer E. Smith · Heike K. Lotze · Paul A. DeSalles · Suzanne N. Arnold • Boris Worm
}

Received: 25 May 2010 / Accepted: 11 August 2010 / Published online: 26 August 2010

(C) The Author(s) 2010. This article is published with open access at Springerlink.com

\begin{abstract}
Large animals are severely depleted in many ecosystems, yet we are only beginning to understand the ecological implications of their loss. To empirically measure the short-term effects of removing large animals from an ocean ecosystem, we used exclosures to remove large fish from a near-pristine coral reef at Palmyra Atoll, Central Pacific Ocean. We identified a range of effects that followed from the removal of these large fish. These effects were revealed within weeks of their removal. Removing large fish (1) altered the behavior of prey fish; (2) reduced rates of herbivory on certain species of reef algae; (3) had both direct positive (reduced mortality of coral recruits) and indirect negative (through reduced grazing pressure on competitive algae) impacts on recruiting corals; and (4)
\end{abstract}

Communicated by F. Bulleri.

D. J. McCauley $(\bowtie) \cdot$ F. Micheli

Hopkins Marine Station, Stanford University,

Pacific Grove, CA 93950, USA

e-mail: dougm@stanford.edu

H. S. Young · P. A. DeSalles

Biology Department, Stanford University,

Stanford, CA 94305, USA

D. P. Tittensor $\cdot$ H. K. Lotze · B. Worm

Biology Department, Dalhousie University,

Halifax, NS B3H 4J1, Canada

D. R. Brumbaugh · K. E. Holmes

Center for Biodiversity and Conservation,

American Museum of Natural History,

New York, NY 10024, USA

D. R. Brumbaugh

Institute of Marine Sciences, University of California,

Santa Cruz, CA 95060, USA tended to decrease abundances of small mobile benthic invertebrates. Results of this kind help advance our understanding of the ecological importance of large animals in ecosystems.

\section{Introduction}

Human hunters and fishers often selectively target large prey (Pauly et al. 1998; Bird et al. 2001; Jerozolimski and Peres 2003; Myers and Worm 2005). Removing large animals from ecosystems can have important short and long-term ecological effects that can cascade across multiple trophic levels (Baum and Worm 2009; Johnson 2009;
E. M. P. Madin

Department of Ecology, Evolution and Marine Biology,

University of California, Santa Barbara, CA 93106, USA

\section{K. E. Holmes}

Marine Program, Wildlife Conservation Society,

Kavieng, New Ireland Province, Papua New Guinea

\section{J. E. Smith}

Scripps Institution of Oceanography,

University of California San Diego,

La Jolla, CA 92093, USA

S. N. Arnold

Darling Marine Center, University of Maine,

Walpole, ME 04573, USA 
Terborgh and Estes 2010). Removing large predators can cause immediate change by decreasing mortality of prey species, benefiting smaller competitors, or altering prey behavior (Pace et al. 1999; Preisser et al. 2005; Heithaus et al. 2008). Likewise, removing large herbivores and omnivores can have immediate direct and indirect impacts on their forage base and smaller-bodied competitors (Berger et al. 2001; Pringle et al. 2007).

Research on the importance of large animals in terrestrial ecosystems has been significantly advanced by studies conducted in systems that retain moderately intact large animal communities (e.g. Sinclair and Norton-Griffiths 1995; Terborgh et al. 2001). Following this model in the oceans has been problematic because densities of large marine animals were greatly reduced in many accessible ocean ecosystems prior to the onset of most modern marine ecological research (Dayton et al. 1998; Lotze et al. 2006). Much of the literature on the ecological role of "large" marine animals has been generated in ecosystems already depleted of their large fauna (Jackson 1997). Conclusions generated within these impacted baselines provide an incomplete understanding of the importance of large marine animals to ecosystems and the significance of their loss.

In order to directly investigate the ecological impact of removing large animals from a marine ecosystem, we used exclosures to experimentally remove large animals from a rare example of a near-pristine coral reef ecosystem at remote Palmyra Atoll, in the central Pacific Ocean. Palmyra has one of the highest documented biomasses of large coral reef fish in the world (Stevenson et al. 2007; DeMartini et al. 2008). We measured the effects of the removal of large fish in this system on: (1) fish abundance and community structure, (2) the behavior of prey fish, (3) algal communities, (4) coral recruitment, and (5) mobile benthic reef invertebrates. These five variables were chosen because they involve processes that are fundamental to coral reef community structure and function and because they operate at spatial and temporal scales small enough to be meaningfully measured using the methods we selected. Results from this work help us to better understand the ecological implications of depletions of large fish and provide valuable information about how marine reserves and other management actions that successfully recover large fish stocks may affect ecosystem properties.

\section{Methods}

Study site

Palmyra Atoll $\left(5^{\circ} 52^{\prime} \mathrm{N}, 162^{\circ} 04^{\prime} \mathrm{W}\right)$, in the Northern Line Islands, has been mostly uninhabited, save for a brief, but intense, occupation by the US military during World War II. Currently, the atoll is managed as a National Wildlife Refuge by the US Fish and Wildlife Service where all fishing is prohibited. We conducted our experiments on the atoll's northern forereef (exposed to open ocean), where densities of large fish are particularly high (McCauley, unpublished data).

Other large animals in the Palmyra forereef community include sea turtles and marine mammals. However, their abundances at Palmyra are low relative to the abundance of large fish. Macro-invertebrate densities on Palmyra's forereef are so low as to be unmeasurable (Miller et al. 2008). Given the dominance of large fish in this community, the focus of this experiment was on the impact of their removal.

\section{Exclosure experiment}

Three experimental treatments were used to investigate the ecological impacts of removing large fish from the forereefs of Palmyra: (1) full exclosures (F) with $5 \times 5 \mathrm{~cm}$ mesh, designed to reduce abundances of fish $10-25 \mathrm{~cm}$ total length (TL) and completely exclude fish $>25 \mathrm{~cm}$ TL; (2) partial exclosures (P) (Fig. 1), constructed in the same fashion but with six $75 \times 75 \mathrm{~cm}$ holes cut in their sides to allow both small and large fish to enter, and (3) completely open plots $(\mathrm{O})$. The partial exclosure treatments provided an experimental control to compare against open treatments and test for possible exclosure artefacts (e.g. shading, reduced water flow).

Palmyra's large coral reef fish encompass a variety of feeding guilds including: piscivores, herbivores, corallivores, non-coral invertivores, detritivores, and omnivores. Exclosures removed fish $>25 \mathrm{~cm}$ TL without regard to their function. In this way, they mimicked the size-selective harvest strategies of many fisheries and matched size specific depletion trends observed in this region (DeMartini et al. 2008).

Full and partial exclosures were constructed of durable polyethylene construction fencing supported by a domeshaped PVC frame, anchored to the substrate using stainless steel posts. The basal diameter of these hemispherical exclosures was $3.5 \mathrm{~m}$ and the maximum radial height was $1 \mathrm{~m}$. A 75-cm-wide flexible mesh skirt was sealed to the substrate at the base of the exclosure using cable ties to prevent unwanted incursions of large fish. Each treatment was replicated four times, for a total of twelve experimental plots. The experiment was installed at $13 \mathrm{~m}$ depth with plots spaced $20 \mathrm{~m}$ apart. Treatment designations $(\mathrm{F}, \mathrm{P}$, or $\mathrm{O})$ were randomly determined. Fouling on exclosures was minimal during the time course of the experiment. Spots of minor growth, when observed on exclosures, were removed. The experiment was installed in July 2007 and removed in November 2007. 

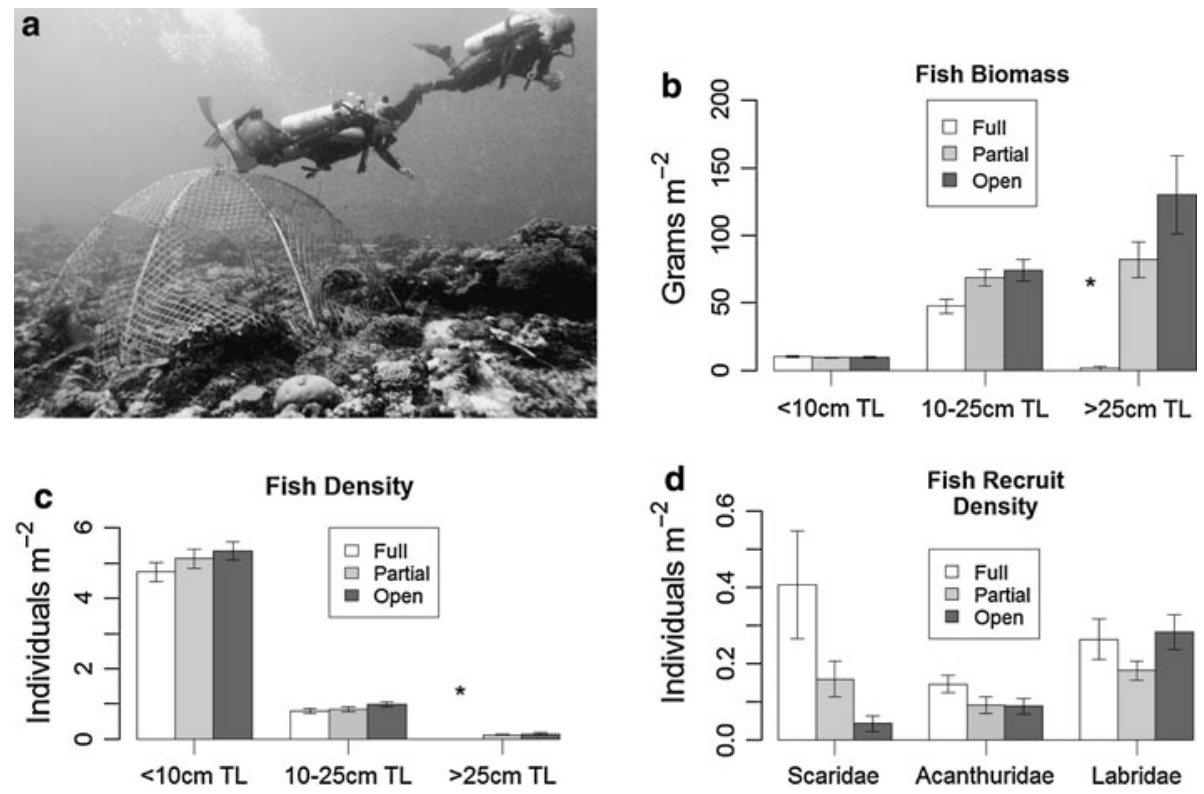

Fig. 1 An example (a) partial exclosure. Responses of $\mathbf{b}$ fish biomass and $\mathbf{c}$ density to exclosure treatment (mean $\pm \mathrm{SE}$ ). Effects of treatment on $\mathbf{d}$ fish recruit density from the three families with the highest rates of recruitment (mean $\pm \mathrm{SE}$ ). All data is from SCUBA surveys. Asterisks mark the treatments that significantly differ from open treatments.

Large fish were much reduced in full plots indicating that total exclosures functioned properly. Removal of large fish from full exclosures did not affect the biomass or density of fish $\leq 10 \mathrm{~cm}$ total length $(T L)$, but caused marginal, although non-significant, increases in the recruitment of fish from families Scaridae and Acanthuridae

To directly test whether full or partial exclosures significantly blocked light, we installed sensors (Onset Computers) that logged light level every $10 \mathrm{~s}$ for 7 days at the center point of three plots in each of the three treatments. To test whether exclosures affected water flow, we placed three dissolution blocks constructed of lab grade dental plaster in the center of all experimental plots for 4 days. The difference in dry mass of blocks before and after deployment was used to approximate and compare rates of flow (Bertness et al. 2002).

Fish communities

Fish were surveyed by two observers (taxa divided evenly between observers) within each experimental plot using a modified point count method (Samoilys and Carlos 2000). For a period of $5 \mathrm{~min}$, all fish inside the dome-shaped boundaries of each treatment (boundaries of open plots demarked to aid in visualization) were identified to species, counted, and their length was estimated visually to the nearest $5 \mathrm{~cm}$. The first minute of each survey was conducted with observers remaining $10 \mathrm{~m}$ from the plot under observation to properly record easily intimidated species. Fish surveys were conducted approximately weekly for a total of 13 replicate observations for each plot.

Because large fish at Palmyra may be affected by the presence of SCUBA divers, we used seafloor mounted video cameras that filmed whole plots to supplement data

from SCUBA observations. Video cameras captured data in a subset of the plots continuously for 30-90 min while divers were not in the water. All recordings were made during daylight hours for a total of $1,605 \mathrm{~min}$ of video. In the video analysis, all fish $\geq 15 \mathrm{~cm}$ TL that entered plot boundaries were counted and their approximate size was estimated in $5 \mathrm{~cm}$ increments based on reference points of known size in the frame of view. All attempts were made to count individual fish recorded on video only once: fish that appeared in consecutive frames and uniquely marked fish that reappeared during the same video survey were counted one time only. To standardize these observations, the total biomass of all fish observed in any given video was normalized by the film time.

Given our experimental context, it is only meaningful to test for the effects of large fish removal on small fish whose home-ranges were wholly or partly enclosed by the exclosures. Values from the literature and observation at Palmyra suggest that fish $\leq 10 \mathrm{~cm}$ TL best meet this criterion (Madin et al. in press; Kramer and Chapman 1999; McCauley, unpublished data). Thus, when evaluating the response of small fish communities to large fish removal, we only compare the density, biomass, and species richness of communities of fish $\leq 10 \mathrm{~cm}$ TL. In these comparisons, we decided a priori to remove data from the first four fish surveys to eliminate the initial period when fish may have been adjusting to the experiment. Changes in densities of fish recruits in the experiment were calculated for families in which 
recruitment was high enough to be measurable (Acanthuridae, Labridae, and Scaridae). We also compared community composition of fish $\leq 10 \mathrm{~cm} T L$, at the species level, across treatments. Throughout fish biomass was estimated using length-weight conversion factors obtained from FishBase (Froese and Pauly 2009) or published literature.

SCUBA data was the only data source used to measure the direct effects of removing large fish on $\leq 10 \mathrm{~cm}$ TL small fish communities. SCUBA data was also used to evaluate the general effects of partial and total treatments on medium (10-25 cm TL) and large fish ( $>25 \mathrm{~cm} \mathrm{TL})$ and to investigate causality for patterns of fish behavior. However, because video data likely provides a better way to measure large fish abundance than SCUBA data, we used video data to determine which large fish families were removed from full exclosures and if and how specific fish families may have been affected by the partial exclosure treatments.

\section{Fish behavior}

To determine whether the behavior of small prey fish changed with the removal of large predatory fish, we measured the foraging behavior of the abundant damselfish Chromis margaritifer. This small-bodied ( $<9 \mathrm{~cm}$ TL) species makes cautious foraging excursions from a benthic refuge a short distance into the water column to feed on plankton. When alarmed, C. margaritifer, like many reef fish, reduces its hovering height in the water column or dives directly into the protective reef structure. We recorded the hovering height (straight line distance from fish to nearest refuge in the reef) of a focal $C$. margaritifer every $10 \mathrm{~s}$ for $5 \mathrm{~min}$ (as described in Madin et al. in press) during daylight hours, with observers $\sim 2.5 \mathrm{~m}$ from focal fish. Individual C. margaritifer closest to the marked center point of each plot were selected for observation. C. margaritifer has been shown in a separate study in the same reef system to move on average approximately $5 \mathrm{~cm}$ from refuge when no immediate predator is present (Madin et al. in press). The $3.5 \mathrm{~m}$ diameter and $1 \mathrm{~m}$ height of the exclosures therefore represent 70 and 20 times, respectively, longer distances than they would normally venture from shelter. Although C. margaritifer appeared generally unaffected by divers, observers waited $2 \mathrm{~min}$ before taking data on a focal fish to allow them to become accustomed to their presence. During each observation, we estimated the total length of focal fish as well as the group size of the conspecifics with which the focal fish associated. There were no significant differences for the total length of focal fish or of their conspecific group size in the different treatments.

Behavioral surveys began 1 month after the installation of the experiment. The behavior of focal fish (F, $N=23$; P,
$N=21 ; \mathrm{O}, N=20$ ) was monitored in six surveys evenly spaced over the course of the experiment. Fish were not marked to avoid negatively conditioning them to divers. We cannot, therefore, rule out the possibility that data were taken on the same individual more than once over the course of the experiment.

\section{Algal communities}

The response of algal communities to the removal of large fish was measured in three ways: (1) benthic algae communities were monitored using recruitment tiles, (2) herbivory on macroalgae was measured using feeding assays, and (3) abundance of locally dominant macroalgae Halimeda spp. was measured using photographic sampling.

Algal community development was measured on unglazed terracotta settlement tiles. Five $10 \mathrm{~cm} \times 10 \mathrm{~cm} \times$ $1 \mathrm{~cm}$ tiles were attached to the substrate in each experimental plot. Benthic algae on tiles were non-destructively sampled at month one, two, and four of the experiment. Tiles were collected and brought back to the lab where we photographed their top surfaces. During transport and analysis tiles were stored without contacting one another in aerated seawater tanks maintained at ambient reef temperature. Tiles were returned in $<24 \mathrm{~h}$ to their exact location and orientation in the experiment. To estimate the percent cover of benthic algae on tiles, we analyzed tile photographs using the software CPCe (Kohler and Gill 2006). All algal species on tile surfaces were pooled into two categories: "CCA" (live and dead crustose coralline algae; mainly Porolithon onkodes, but also Paragoniolithon conicum, Neogoniolithon frutescens, N. rufum, and N. clavycymosum) and "non-CCA" (mainly Lobophora spp. and Peyssonnelia spp., but also green encrusting algae (e.g. Ulvella spp.), filamentous algae, turf algae, and cyanobacteria). Statistical analyses were conducted on the percent cover of CCA and non-CCA at the end of the experiment (month four). These same tiles were used to study rates of coral recruitment as discussed below.

To determine how large fish removal affected rates of herbivory on reef macroalgae, we measured feeding rates on five species of erect green macroalgae in each treatment: Halimeda opuntia, Halimeda taenicola, Caulerpa serrulata, Dictyosphaeria cavernosa, and Avrainvillea amadelpha. All of these species are found on the forereef in the vicinity of the exclosure installation, although only calcified $H$. taenicola and $H$. opuntia are common. Pieces of each of the five species of algae were field collected, trimmed to a consistent size ( $\sim 7 \mathrm{~cm}$ lengths), and presented in a random order to herbivores in feeding arrays (PVC tubes with clothes pins) mounted to the substrate in each experimental unit. To measure biomass change, each piece of algae was blotted dry and weighed before and after being 
deployed. Pieces were left in the field for 2-3 days, contingent on rates of consumption. Biomass change was measured as weight change per $24 \mathrm{~h}$. The few pieces that were completely missing from arrays were not included in biomass comparisons given the possibility that they had been removed by currents or pulled from pins by herbivores and not entirely consumed. We do, however, report the frequencies at which whole pieces of algae were removed. To determine the identity of the herbivores consuming the macroalgae in these arrays, we video recorded feeding arrays at the conclusion of the experiment. We conducted these video trials with four of the five macro-algal species used in the exclosure experiment (Halimeda taenicola not included because of its functional similarity to $H$. opuntia). Videos of herbivores feeding on algae in these arrays ran continuously for $90 \mathrm{~min}$ while divers were absent. Filming was conducted during daylight hours for a total of 2,494 min of video.

To compare in situ changes in macro-algal abundance between treatments, we photographed or took video of the $1 \mathrm{~m}^{2}$ circular area at the center of each treatment before experimental installation and at month three of the experiment. Halimeda was the only genus of macroalgae at this site that was abundant and conspicuous enough to be compared using these images. Two species of Halimeda (H. opuntia and H. taenicola) occurred at the experimental site, but were pooled for analysis. The percent cover of Halimeda spp. in each plot was measured from images using the software Vidana (Hedley 2003).

\section{Coral recruitment}

Rates of coral recruitment were measured on the same tiles used to monitor benthic algae. Data on coral recruitment were gathered synchronously with benthic algal data collection at months one, two, and four. Only the top surfaces of tiles were reviewed in these surveys. At month one, counts of recruits were made by fluorescing and counting recruits using blue light (Baird et al. 2006) and conducting random visual searches using a dissecting microscope. Although the percentage of non-fluorescing coral recruits can vary over time, most recruits at Palmyra consistently fluoresce (Brumbaugh, personal observation). Blue light counts and visual searches produced the same results in month one, thus, only blue light fluorescence was used in subsequent counts. The location of metamorphosed recruits on each tile was mapped. These maps allowed us to record numbers of newly settled recruits (i.e. those that had not been present during prior counts) separately from the total number of recruits on tiles (i.e. newly settled recruits + surviving recruits from previous observations). A subset of coral recruits on tiles were identified to be in families Poritidae and Pocilloporidae. However, the overall difficulty of identifying recruits at this life stage prevented us from conducting taxon specific analyses.

\section{Benthic invertebrate density}

The density of small mobile reef benthic invertebrates was measured using artificial invertebrate collectors (Tuffy ${ }^{\circledR}$ brand scrub pads) (Broitman et al. 2008). Five sterilized collectors were affixed to the reef in each treatment at the start of the experiment and removed at month three. The small size of these collectors confined us to considering the effects of our experimental treatments on small-bodied (generally $<2 \mathrm{~cm}$ ) invertebrates only. Upon retrieval, collectors were frozen and later washed onto a $150-\mu \mathrm{m}$ sieve. Invertebrates were separated from the filter, identified, and counted. Only gastropods, bivalves, malacostracan crustaceans, and ophiuroid echinoderms were included in this analysis. Other invertebrates were either too rare or were unidentifiable after freezing. Given low abundances, samples were pooled by class for analysis.

\section{Statistical analysis}

We employed a generalized linear mixed model (GLMM) approach (Gelman and Hill 2006) to deal with violations of statistical assumptions of normality and independence in much of our experimental data. These violations rendered more traditional approaches inapplicable (Bolker et al. 2009). In particular, count data (e.g. coral recruits per tile) had non-normal error distributions, and data within treatments were correlated.

Hierarchical linear mixed effects models (replicate plots nested within treatments, individual plots as random effects) were used to determine whether there were significant differences between treatments for light level; water flow; density of fish recruits; fish density, biomass, and species richness; percent cover of the benthic algae on recruitment tiles; and percent cover of the dominant macroalga Halimeda. In instances where temporally replicated measurements of a response variable were taken, an autoregressive correlation structure was adopted. GLMM were used to analyze coral recruit and benthic invertebrate data assuming a Poisson distribution and a quasi-Poisson distribution, respectively. We use the Laplacian approximation for parameter estimation. The ar1 autoregressive structure was employed throughout. When there was evidence for overdispersion, we used Wald $t$-tests for hypothesis testing and when there was no evidence for overdispersion we used Wald $Z$ tests (Bolker et al. 2009).

To account for the possibility of non-independence in the fish behavior data, we conservatively pooled data on the hovering height, total length, and group size of focal fish to create averages for each experimental replicate and analyzed 
these using a one-way ANOVA and paired two-tailed Welch's $t$-tests; $\alpha$ values were adjusted using a Holm-Bonferroni correction. Given the large home range size of $>15 \mathrm{~cm}$ TL fish, video data of these large fish were treated independently and compared between partial exclosures and open plots using two-tailed Welch's t-tests or Wilcoxon's tests (when parametric assumptions could not be met).

To normalize data when necessary, transformations were performed for flow data $(\log )$, certain $\geq 15 \mathrm{~cm}$ TL fish taxa in video data $(\log (x+1))$, percent cover of benthic algae on tiles (arcsine square root), change in percent cover of Halimeda spp. (arcsine), and herbivory data on algae A. amadelpha, C. serrulata, and $H$. fragilis $(\log (x+1))$. In most instances, reports from statistical tests compare results from full $(\mathrm{F})$ and partial exclosure treatments $(\mathrm{P})$ to open plots (O) after the fashion: F vs. $\mathrm{O}, P=\mathrm{X}$; P vs. $\mathrm{O}, P=\mathrm{Y}$. Our experimental design does not necessitate that comparisons be made between full and partial treatments. All of the above statistics were computed in R v. 2.7.0 (R Development Core Team 2008), using packages lme4 (Bates and Maechler 2009) and MASS (Venables and Ripley 2002).

The composition of $\leq 10 \mathrm{~cm}$ TL fish communities were compared between treatments at the species level using multivariate analysis conducted in PRIMER. Bray-Curtis dissimilarity between communities in different treatments was calculated on square-root transformed biomass data. We conducted 2-way analyses (treatment and time) of similarity (ANOSIM) to test if structure of fish assemblages differed between treatments.

\section{Results}

Fish communities

Data from SCUBA surveys indicated that the total exclosures effectively excluded large fish $>25 \mathrm{~cm}$ TL (biomass $\mathrm{F}$ vs. $\mathrm{O}, t=-3.28, P<0.01$; density $\mathrm{F}$ vs. $\mathrm{O}, t=-5.13$, $P<0.001$; Fig. 1) and reduced the biomass (albeit non-significantly), but not the density, of medium sized fish $10-25 \mathrm{~cm}$ TL (biomass: $\mathrm{F}$ vs. $\mathrm{O}, t=-2.0, P=0.07$; density: $\mathrm{F}$ vs. $\mathrm{O}, t=-1.6, P=0.14)$. The composition of large fish observed in open plots using video surveys, by inference, also provides data on the identity and quantity of large fish that were removed from the full exclosures. Corallivorous/ herbivorous parrotfish in the family Scaridae were the most common large fish removed, accounting for $26.5 \%$ of the biomass of excluded fish. They were followed by, in decreasing order, fish in families Acanthuridae (20.6\%, surgeonfish: herbivore, detritivore), Carcharhinidae (19.2\%, reef sharks: piscivore, invertivore), Labridae (10.8\%, wrasse: piscivore, invertivore), Serranidae (9.4\%, grouper: piscivore), Lutjanidae (5.3\%, snapper: piscivore, inverti- vore), Mullidae (4.0\%, goatfish: invertivore) Balistidae (2.8\%, triggerfish: invertivore), Carangidae (1.1\%, jacks: piscivore, invertivore), and Chaetodontidae $(0.4 \%$, butterflyfish: corallivore, invertivore). Results indicated that exclosures did not significantly impede light passage ( $F$ vs. $\mathrm{O}, P=0.48$; $\mathrm{P}$ vs. $\mathrm{O}, P=0.21$ ), nor water flow (as inferred using dissolution blocks; $\mathrm{F}$ vs. $\mathrm{O}, P=0.28 ; \mathrm{P}$ vs. $\mathrm{O}$, $P=0.15$ ).

Results from SCUBA and video surveys provide different viewpoints on how partial exclosures function relative to open plots. SCUBA data indicated that the density and biomass of $10-25 \mathrm{~cm}$ TL fish (biomass $\mathrm{P}$ vs. $\mathrm{O}, t=-0.42$, $P=0.69$; density $\mathrm{P}$ vs. $\mathrm{O}, t=-1.3, P=0.23$; Fig. 1 ) and $>25 \mathrm{~cm}$ TL fish (biomass $\mathrm{P}$ vs. $\mathrm{O}, t=-1.2, P=0.25$; density $\mathrm{P}$ vs. $\mathrm{O}, t=-0.8, P=0.45)$ did not differ significantly between open and partial treatments (Fig. 1). Video data, which is likely to be a superior measure of the abundance of wary large fish, suggested, however, that partial exclosures reduced the abundance of certain functionally important fish families. Video results indicated that fish $>15 \mathrm{~cm}$ TL in the families Scaridae ( $W=47, P=0.05)$, Labridae $(t=4.8$, $P<0.001)$, Serranidae $(W=49, \quad P=0.03)$, Mullidae $(t=3.2, P=0.02)$, Acanthuridae $(t=2.3, P=0.04)$, and Balistidae $(W=47, P=0.04)$ were significantly less abundant in partial exclosures than open plots. Members of family Carcharhinidae were detected in open plots, but not partial treatments. No differences were observed between open and partial treatments for fish in families Lutjanidae $(t=-0.9, P=0.39)$, Carangidae $(W=28.5, P=1.0)$, and Chaetodontidae $(W=37, \quad P=0.22)$. Lethrinids were detected in partial plots, but not open treatments. Because video observed abundances of large fish from multiple important feeding guilds in partial exclosures appeared to be roughly intermediate between open plots and full exclosures, we revised our expectation that results in partial exclosures should match open plots.

The removal of large fish had no significant impact on the density (F vs. O, $t=-0.79, P=0.45 ; \mathrm{P}$ vs. O, $t=-0.34, P=0.74$ ), biomass (F vs. $\mathrm{O}, t=0.68, P=0.51 ; \mathrm{P}$ vs. $\mathrm{O}, t=-0.37, P=0.72$ ), species richness (F vs. $\mathrm{O}$, $t=-1.44, P=0.18$; P vs. $\mathrm{O}, t=-1.50 P=0.17$ ), or community composition (global $R=-0.04, P=0.81$; F vs. $\mathrm{O}$, $R=0.02 P=0.34 ; \mathrm{P}$ vs. $\mathrm{O}, R=-0.04, P=0.75)$ of $\leq 10 \mathrm{~cm}$ TL fish (the size class that had free access to all experimental plots, Fig. 1).

Rates of fish recruitment were low throughout the experiment. Recruitment was only measurable for fish in families Acanthuridae, Labridae, and Scaridae (Fig. 1). Density of recruits was noticeably higher inside full exclosures than other treatments for Scarid recruits, but none of the differences for these three families were statistically significant (Scaridae: $\mathrm{F}$ vs. $\mathrm{O}, t=1.46, P=0.18 ; \mathrm{P}$ vs. $\mathrm{O}, t=0.41$, $P=0.69$; Acanthuridae: F vs. $\mathrm{O}, t=0.97, P=0.36$; $\mathrm{P}$ vs. $\mathrm{O}$, 
$t=0.05, P=0.96 ;$ Labridae: $\mathrm{F}$ vs. $\mathrm{O}, t=-0.09, P=0.93 ; \mathrm{P}$

vs. $\mathrm{O}, t=-0.95, P=0.37$; Fig. 1 ).

Fish behavior

Small prey fish C. margaritifer ventured on average the furthest from safe refuge in full exclosures (Fig. 2; F vs. O, $t=6.31, P<0.001)$. Average distances traveled from refuge in partial exclosures were intermediate to values recorded in full exclosures and open plots ( $\mathrm{P}$ vs. $\mathrm{O}, t=2.91$, $P=0.02$; post-corrected $\alpha=0.025$ ). Regressions of mean biomass of predatory fish observed in SCUBA counts in each plot vs. mean hovering height of $C$. margaritifer in each plot demonstrated a significant negative relationship $\left(r^{2}=0.4 ; P=0.03\right)$.

\section{Algal communities}

Analyses of recruitment tiles indicated that there were no significant differences in the percent cover change of CCA growing on tiles between treatments ( $\mathrm{F}$ vs. $\mathrm{O}, t=-0.80$, $P=0.45$; $\mathrm{P}$ vs. $\mathrm{O}, t=-0.46, P=0.66$ ). However, the percent cover of non-CCA algal groups was significantly higher in full exclosures where large fish had been excluded compared to open plots (F vs. $\mathrm{O}, t=2.57 P=0.03$; P vs. O, $t=0.99 P=0.35$ ) (Fig. 3).

Grazing assays indicated that herbivory on the macroalga A. amadelpha (F vs. $\mathrm{O}, t=-3.4, P<0.01 ; \mathrm{P}$ vs. $\mathrm{O}$, $t=-1.3, P=0.22$ ) and $D$. cavernosa (F vs. $\mathrm{O}, t=2.02$, $P=0.07$; $\mathrm{P}$ vs. $\mathrm{O}, t=1.36, P=0.21)$ were significantly and

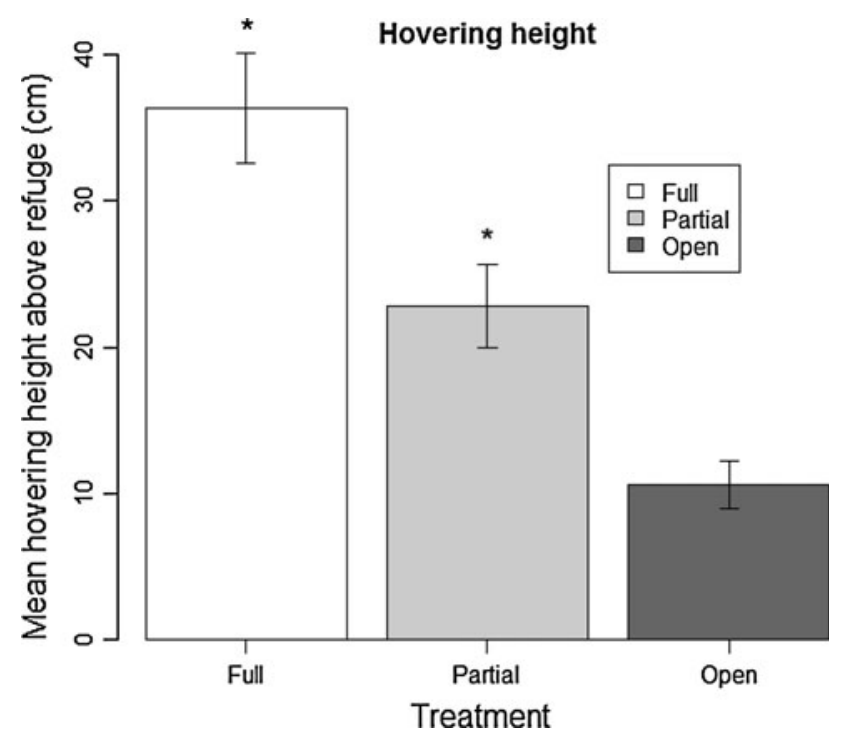

Fig. 2 Distance that the small planktivorous fish Chromis margaritif$e r$ hovered above refuge points (mean $\pm \mathrm{SE}$ ). Asterisks mark the treatments that significantly differ from open treatments. These prey fish foraged the farthest from safety in full exclosures where large predators had been removed

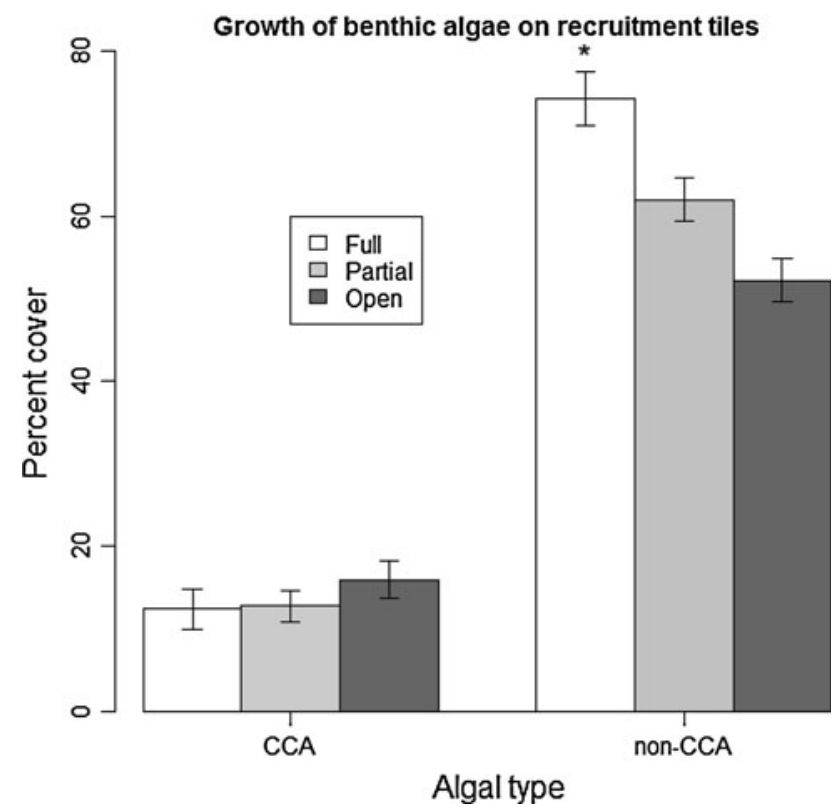

Fig. 3 Percent cover of benthic algae on recruitment tiles at the end of the experiment (mean \pm SE). CCA: live/dead crustose coralline algae; non-CCA: all other benthic growth (excluding corals). Asterisks mark the treatments that significantly differ from open treatments. The percent cover of non-CCA was significantly higher in full exclosures than in open plots, but no differences were evident between treatments for better defended CCA

near-significantly higher, respectively, in open plots where large fish had access to algae relative to the full exclosures (Fig. 4). There was considerably less grazing on the other macroalgae $C$. serrulata, $H$. taenicola, and $H$. fragilis. Biomass change of these three algae was not significantly different between treatments. Rates of removal of whole pieces of algae were generally quite low-the mean rate for the complete loss of a piece of algae across the five taxa was $3.6 \%( \pm 1.4 \% \mathrm{SE})$. Rates of whole piece removal were highest in open plots for D. cavernosa and H. taenicola; and highest but tied between open plots and partial exclosures for $A$. amadelpha and $C$. serrulata. No pieces were lost for $H$. fragilis. In video observations of macro-algal herbivory assays, only fish were observed to feed on the algae. While video only provides insight into diurnal patterns of herbivory, the near-absence of key nocturnal herbivores (i.e. urchins) and the correspondence of patterns of algal biomass loss with video herbivory data, suggest that it is reasonable to conclude that diurnal fish are the major consumers of macroalgae on Palmyra's reefs. The two macroalgae that lost biomass outside of the full exclosure treatments (A. amadelpha and D. cavernosa) were observed in the video to have been consumed by fish from families Scaridae, Acanthuridae, and Pomacentride. Ninety-five percent of the bites from fish $>15 \mathrm{~cm}$ TL (those that removed the largest biomass of algae) on A. amadelpha were delivered by parrotfish Calotomus carolinus, but herbivory was 


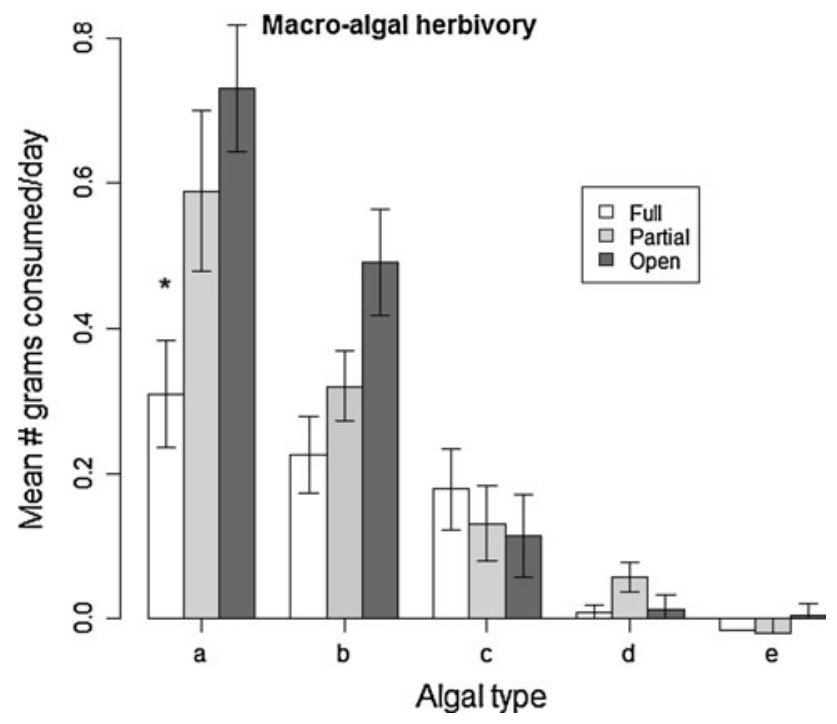

Fig. 4 Differences in herbivory on macroalgae (a) Avrainvillea amadelpha, (b) Dictyosphaeria cavernosa, (c) Caulerpa serrulata, (d) Halimeda taenicola, and (e) Halimeda opuntia (mean grams consumed day ${ }^{-1} \pm \mathrm{SE}$ ). Asterisks mark treatments that significantly differ from open treatments. Herbivory on A. amadelpha and D. cavernosa was significantly and near-significantly, respectively, reduced in full exclosures where large herbivorous fish were excluded (relative to open treatments)

also observed by surgeonfish Acanthurus nigricauda and Naso lituratus. Herbivory by $>15 \mathrm{~cm}$ TL fish on D. cavernosa was more evenly distributed among species and caused by (in decreasing order of number of bites) parrotfish Scarus altipinnis and the four surgeonfish A. nigricauda, N. lituratus, Ctenochaetus marginatus, and Ctenochaetus striatus; although the latter two species appeared primarily to feed on macroalgae epiphytes or surface biofilms.

Images of the benthos in each of the experimental plots indicated that over the course of this experiment, the mean percent cover of dominant macroalgae Halimeda spp. declined in open plots where large fish had free access $(-8.0 \%)$ and marginally increased in partial $(1.5 \%)$ and full large fish exclosures $(1.4 \%$ ) (F vs. $\mathrm{O}, t=2.56, P=0.03 ; \mathrm{P}$ vs. $\mathrm{O}, t=2.40, P=0.04)$.

\section{Coral recruitment}

Patterns in the abundance of metamorphosed recruits on tiles between treatments changed over the course of the experiment. The total number of recruits was highest in total exclosures at month one (F vs. $\mathrm{O}, Z=3.34, P<0.001$; $\mathrm{P}$ vs. $\mathrm{O}, Z=1.64, P=0.10$ ) and month two (F vs. $\mathrm{O}$, $Z=2.14, P<0.03$; P vs. $\mathrm{O}, Z=1.52, P=0.13$ ); but there were no significant differences in the final review at month four (F vs. $\mathrm{O}, Z=0.94, P=0.35 ; \mathrm{P}$ vs. $\mathrm{O}, Z=1.22$, $P=0.22$; Fig. 5). When analyzed on their own, the abundance of newly settled recruits showed a similar pattern.

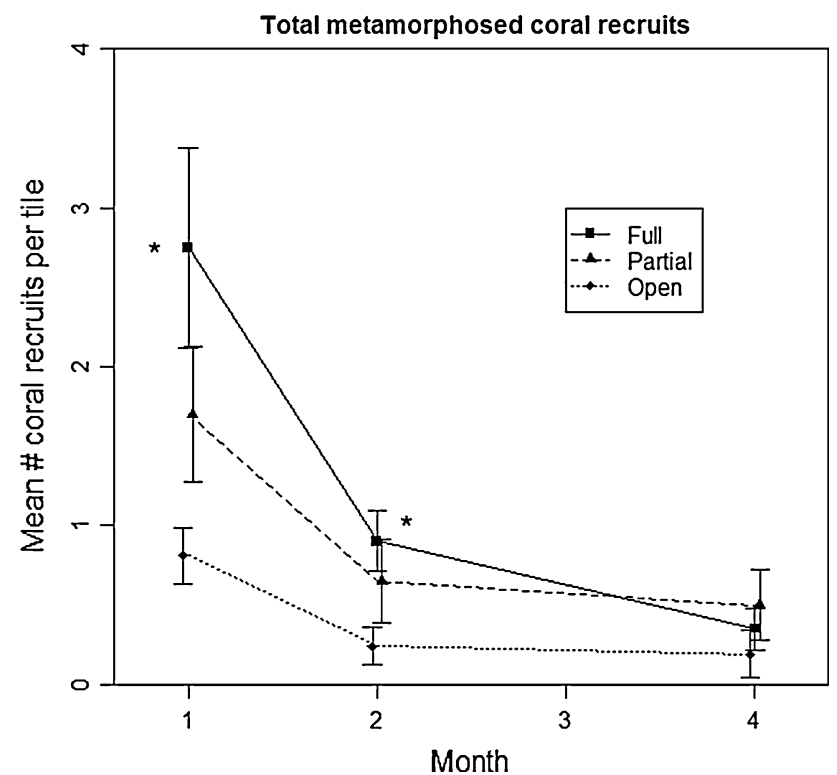

Fig. 5 Total abundance of metamorphosed coral recruits (new settlers + surviving recruits) on tiles (mean/tile \pm SE). Asterisks mark the treatments that significantly differ from open treatments. In month one and two, rates of recruitment were significantly higher inside full exclosures where recruits were protected from large herbivorous fish, but this difference diminished by month four

The average number of newly settled recruits was highest in total exclosures at month one (F vs. $\mathrm{O}, Z=3.62$, $P<0.001$; P vs. $\mathrm{O}, Z=2.0, P=0.04)$, but there were no significant differences between treatments in month two (F vs. $\mathrm{O}, Z=0.69, P=0.49$; $\mathrm{P}$ vs. $\mathrm{O}, Z=0.04, P=0.97)$ and month four (F vs. $\mathrm{O}, Z=0.08, P=0.94$; $\mathrm{P}$ vs. $\mathrm{O}, Z=0.92$, $P=0.36)$.

Benthic invertebrate density

Mean numbers of benthic invertebrates (pooled by class) were higher in open plots and partial exclosures than full exclosures (mean $\pm \mathrm{SE}$ : $\mathrm{O}=32.1 \pm 3.1 ; \mathrm{P}=29.1 \pm 3.8$; $\mathrm{F}=23.6 \pm 2.4$ ) but these differences were not statistically significant (F vs. $\mathrm{O}, t=-2, P=0.08$; $\mathrm{P}$ vs. $\mathrm{O}, t=-1$, $P=0.53$ ). The overall rarity of these invertebrates prevented robust analyses from being conducted with individual classes, although trends at the class level qualitatively mirrored trends observed when classes were pooled.

\section{Discussion}

Large fish exclosures, mimicking size-selective removal of consumers through fishing, caused a suite of rapid changes to occur in a coral reef community. In particular, the shortterm removal of large fish altered the behavior of a small prey fish, but not the abundance, diversity, or community 
composition of small fish $(\leq 10 \mathrm{~cm}$ TL); reduced rates of herbivory on certain macroalgae; appeared to facilitate the growth of less preferred benthic algae; had direct positive and indirect negative effects on recruiting corals; and tended to decrease abundances of mobile reef invertebrates, albeit non-significantly. As with all carefully designed exclosure experiments, we have endeavored to separate out the effects of large fish removal on response variables from the potential effects of experimental artefacts. Our direct measurements of light level and flow indicate that there were no significant differences for these two potentially important artefacts. Nevertheless, this lack of significant differences does not provide definitive proof of the negligible effects of exclosure artefacts. Below we discuss the changes that we observed in this experiment, offer our best interpretations of the mechanisms that caused these changes, and consider interactions between multiple response variables.

\section{Fish communities}

The removal of large fish had no effect on the density, biomass, diversity, or composition of $\leq 10 \mathrm{~cm}$ TL small fish communities (Fig. 1). This lack of response contrasts with the findings of exclosure experiments which have demonstrated that removing large fish (particularly predators) regulates small fish recruitment, mortality, density, and relative abundance (Hixon and Carr 1997; Levin et al. 1997; Ceccarelli et al. 2006; Hughes et al. 2007). It is difficult to predict if such effects would also have been observed at Palmyra if it would have been possible to run this experiment for a longer period of time. Trends toward increasing abundance of Scarid recruits at the end of the experiment, although statistically non-significant, suggest a possible mechanism by which long-term differences in small fish abundance might arise.

\section{Fish behavior}

Although there were no measurable numerical effects of large fish removal on small fish abundance or diversity, we observed substantial non-lethal effects on the behavior of small prey fish. The planktivorous damselfish C. margaritifer foraged further from refuges in full exclosures where large fish were absent than in open plots where they were abundant (Fig. 2). This change in behavior is most likely the result of the removal of large piscivorous fish from these full exclosures. Small fish become exposed to increasing risk of predation as they venture further from refuge, but stand to benefit from increased access to food resources by foraging over a larger area. C. margaritifer in full exclosures appear to have perceived the removal of large predators and hence adopted a more optimal behavior pattern.
Average distances traveled from points of refuge by C. margaritifer were greater in partial exclosures than open plots, but still significantly less than full exclosures. These graded differences most likely arose as a result of the variable effectiveness of the different treatments to exclude certain families of large predatory fish, as evidenced by video surveys (e.g. partial cages reduced abundance of certain predators to intermediate levels yielding an intermediate behavioral response by $C$. margaritifer). If, conversely, the behavioral changes we observed for this species arose simply as a result of its response to the physical structure of the exclosures, the expected outcome would have been to observe similar hovering heights for the full and partial exclosures, with decreased heights only in the open treatment. This was not the observed pattern. Our interpretation that these prey fish were responding to the removal of large predators is reinforced by the significant negative relationship observed between mean biomass of predatory fish and mean hovering height of $C$. margaritifer.

Interestingly, hovering heights observed for C. margaritifer in full exclosures, partial exclosures, and open plots approximately match field measured hovering distances recorded by Madin et al. (in press) in three Line Island atolls (including Palmyra) positioned along a fishing gradient with low, medium, and high densities of predatory fish, respectively. The results we observed in this experiment also qualitatively agree with studies of the behavioral effects of predatory fish on a range of taxa (Werner et al. 1983; Helfman 1989; Heithaus and Dill 2002; Stallings 2008).

\section{Algal communities}

We observed that the percent cover of crustose coralline algae (CCA) did not differ between treatments, but that non-CCA increased in full exclosures (Fig. 3). We hypothesize that this increase in non-CCA is the result of the removal of large herbivorous fish. The enhanced structural defenses of CCA generally make them more resistant to large fish grazing (Steneck 1986). Increases in the abundance of non-CCA following reductions in large grazers have been observed in numerous studies conducted in other tropical and temperate systems around the world (Burkepile and Hay 2006; Hughes et al. 2007; Albert et al. 2008).

In like fashion, our macroalgae feeding assays demonstrated that the removal of large fish affects some, but not all species of macroalgae (Fig. 4). A. amadelpha and $D$. cavernosa exhibited the largest reductions in biomass when exposed to large herbivorous fish in open plots. A. amadelpha and $D$. cavernosa may be relatively less well defended against herbivory (although likely not undefended; Meyer et al. 1994) or more preferred by grazers (Lewis 1985) at this site than the three species of macroalgae used in this study that did not respond to exposure to large herbivores 
(Paul and Van Alstyne 1992; Erickson et al. 2006). The total removal of pieces of macroalgae, while relatively a rare occurrence, tended to be highest in treatments where large herbivores had access. Video data demonstrated that large fish, particularly parrotfish and surgeonfish, are the major herbivores of macroalgae at Palmyra.

Analysis of percent change in Halimeda spp. over the course of the experiment (from before/after images) indicated that even though Halimeda spp. were not heavily grazed by large herbivorous fish in open plots during the 2-3 day assays, subtle changes in their abundance did accrue, most likely as the result of prolonged exposure to large herbivorous fish.

The percent cover of non-CCA benthic algae, herbivory of preferred macroalgae species, and percent cover of Halimeda spp. in partial exclosures were intermediate to values recorded in full exclosures and open plots. This pattern is best explained by the fact that the abundance of certain large herbivorous families (e.g. Acanthuridae, Scaridae) was reduced in partial exclosures relative to open plots.

\section{Coral recruitment}

In the first month of the experiment, the highest mean number of metamorphosed coral recruits and mean number of new coral recruits were found in full exclosures (Fig. 5). These differences between treatments disappeared by the end of the experiment. Coral recruits compete with some algal species for space and light but are facilitated by the presence of other algal species. Certain species of CCA have been described to facilitate certain species of coral recruits, while non-CCA are more often considered to be recruitment inhibitors (Harrington et al. 2004; Arnold et al. 2010). We suggest that the high densities of coral recruits observed in full exclosures during the first month of the experiment resulted because there was ample bare tile space early on, competition from nonCCA was low, and recruits profited from the protection the full exclosures provided from large benthic feeding fish (e.g. Scaridae; Bak and Engel 1979; Mumby 2009). But, as time progressed, growth of potential coral inhibiting non-CCA increased in full exclosures (also a result of the removal of large benthic feeding fish) and may have overrode the early positive effects of the exclosures on coral recruits.

\section{Benthic invertebrates}

The mean number of benthic invertebrates found in invertebrate collectors (pooled Gastropoda, Bivalvia, Malacostraca, and Ophiuroidea) was lowest inside the total exclosures. This difference, however, was non-significant, perhaps owing to low sample sizes and high data variance. These putative decreases in invertebrates observed inside exclosures may have resulted from increased feeding efficiency of small invertebrate predators (e.g. Labridae) following the removal of large piscivores. Like the small planktivorous $C$. margaritifer, small invertivores may have undergone behavioral shifts in the absence of predators that allow them to forage more effectively. This would suggest that even though abundances of small fish were not altered by large fish removal, changes in their behavior may cause ecological change.

\section{Conclusions}

Our observations at Palmyra demonstrate that the removal of large animals from near-pristine ecosystems where they are still abundant has direct and indirect effects on coral reef communities, even at small spatial and temporal scales. The variety of responses that we recorded and the rapidity (within weeks) at which these shifts took place suggest that the large reef fish may play an important ecological role in reefs and that their removal can cause immediate change. Additional empirical observation and longer term experiments are needed to understand how ecological change may advance when large fish are removed for more prolonged periods of times.

Pushing forward this kind of science is imperative: large animals have been and continue to be reduced in abundance and size by humans at alarming rates, both on land and in aquatic environments. By endeavoring to describe and quantify the effects of large faunal depletions, we will increase our understanding of how intact ecosystems function and can soberly evaluate the baselines we are and are not managing for.

Acknowledgments We thank the US Fish and Wildlife Service for permission to conduct this research in the Palmyra Atoll National Wildlife Refuge and the staff of the Nature Conservancy for on-site logistical support. Funding was provided for by the National Science Foundation (GRFPs to DJM and EM); the Lenfest Foundation; the Woods Institute for the Environment; the Myers Oceanographic and Marine Biology Trust; a Chambers, and an Alden H. and Winifred Brown Fellowship (FM); and the Jaffe Family Foundation, Pamela Farkas, and NOAA grant number NA055SEC46391002 (DRB and $\mathrm{KEH}$ ). For reviews that improved this manuscript, we thank Rodolfo Dirzo, Jim Estes, and Steve Palumbi. For invaluable field or lab assistance we thank Lisa Max, Kevin McLean, Kevin Laferty, John McCallen, TC Robbins, Lauren Palumbi, Lee Love-Anderegg, Bob Steneck, and the crew of the SSV Robert C. Seamans. This is contribution number PARC-0050 of the Palmyra Atoll Research Consortium.

Open Access This article is distributed under the terms of the Creative Commons Attribution Noncommercial License which permits any noncommercial use, distribution, and reproduction in any medium, provided the original author(s) and source are credited. 


\section{References}

Albert S, Udy J, Tibbetts IR (2008) Responses of algal communities to gradients in herbivore biomass and water quality in Marovo Lagoon, Solomon Islands. Coral Reefs 27:73-82

Arnold SN, Steneck RS, Mumby PJ (2010) Running the gauntlet: inhibitory effects of algal turfs on the process of coral recruitment. Mar Ecol-Prog Ser (in press)

Baird AH, Salih A, Trevor-Jones A (2006) Fluorescence census techniques for the early detection of coral recruits. Coral Reefs 25:7376

Bak RPM, Engel MS (1979) Distribution, abundance and survival of juvenile hermatypic corals (Scleractinia) and the importance of life history strategies in the parent coral community. Mar Biol 54:341-352

Bates D, Maechler M (2009) Lme4: linear mixed-effects models using S4 classes. R package version 0.99. http://CRAN.R-project.org/ package $=1 \mathrm{me} 4$

Baum JK, Worm B (2009) Cascading top-down effects of changing oceanic predator abundances. J Anim Ecol 78:699-714

Berger J, Stacey PB, Bellis L, Johnson MP (2001) A mammalian predator-prey imbalance: grizzly bear and wolf extinction affect avian neotropical migrants. Ecol Appl 11:947-960

Bertness MD, Trussell GC, Ewanchuk PJ, Silliman BR (2002) Do alternate stable community states exist in the Gulf of Maine rocky intertidal zone? Ecology 83:3434-3448

Bird RB, Smith EA, Bird DW (2001) The hunting handicap: costly signaling in human foraging strategies. Behav Ecol Sociobiol 50:9-19

Bolker BM, Brooks ME, Clark CJ, Geange SW, Poulsen JR, Stevens MHH, White JS (2009) Generalized linear mixed models: a practical guide for ecology and evolution. Trends Ecol Evol 24:127135

Broitman BR, Blanchette CA, Menge BA, Lubchenco J, Krenz C, Foley M, Raimondi PT, Lohse D, Gaines SD (2008) Spatial and temporal patterns of invertebrate recruitment along the west coast of the United States. Ecol Monogr 78:403-421

Burkepile DE, Hay ME (2006) Herbivore vs. nutrient control of marine primary producers: context dependent effects. Ecology 87:31283129

Ceccarelli DM, Hughes TP, McCook LJ (2006) Impacts of simulated overfishing on the territoriality of coral reef damselfish. Mar Ecol Prog Ser 309:255-262

Dayton PK, Tegner MJ, Edwards PB, Riser KL (1998) Sliding baselines, ghosts, and reduced expectations in kelp forest communities. Ecol Appl 8:309-322

DeMartini EE, Friedlander AM, Sandin SA, Sala E (2008) Differences in fish-assemblage structure between fished and unfished atolls in the northern Line Islands, central Pacific. Mar Ecol Prog Ser 365:199-214

Erickson AA, Paul VJ, Van Alstyne KL, Kwiatkowski LM (2006) Palatability of macroalgae that use different types of chemical defenses. J Chem Ecol 32:1883-1895

Froese R, Pauly D (eds) (2009) In: FishBase www.fishbase.org, version $(09 / 2009)$

Gelman A, Hill J (2006) Data analysis using regression and multilevel/ hierarchical models. Cambridge University Press, Cambridge

Harrington L, Fabricius K, De' Ath G, Negri A (2004) Recognition and selection of settlement substrata determine post-settlement survival in corals. Ecology 85:3428-3437

Hedley J (2003) Vidana 1.0: video analysis for cover estimation. http:// www.ex.ac.uk/msel/vidana

Heithaus MR, Dill LM (2002) Food availability and tiger shark predation risk influence bottlenose dolphin habitat use. Ecology 83:480-491
Heithaus MR, Frid A, Wirsing AJ, Worm B (2008) Predicting ecological consequences of marine top predator declines. Trends Ecol Evol 23:202-210

Helfman GS (1989) Threat-sensitive predator avoidance in damselfishtrumpetfish interactions. Behav Ecol Sociobiol 24:47-58

Hixon MA, Carr MH (1997) Synergistic predation, density dependence, and population regulation in marine fish. Science 277:946-949

Hughes TP, Rodrigues MJ, Bellwood DR, Ceccarelli D, Hoegh-Guldberg O, McCook L, Moltschaniwskyj N, Pratchett MS, Steneck RS, Willis B (2007) Phase shifts, herbivory, and the resilience of coral reefs to climate change. Curr Biol 17:360-365

Jackson JBC (1997) Reefs since Columbus. Coral Reefs 16:S23-S32

Jerozolimski A, Peres CA (2003) Bringing home the biggest bacon: a cross-site analysis of the structure of hunter-kill profiles in neotropical forests. Biol Conserv 111:415-425

Johnson CN (2009) Ecological consequences of late quaternary extinctions of megafauna. Proc R Soc B Biol Sci 276:2509-2519

Kohler KE, Gill SM (2006) Coral Point Count with Excel extensions (CPCe): a visual basic program for the determination of coral and substrate coverage using random point count methodology. Comput Geosci 32:1259-1269

Kramer DL, Chapman MR (1999) Implications of fish home range size and relocation for marine reserve function. Environ Biol Fishes 55:65-79

Levin P, Petrik R, Malone J (1997) Interactive effects of habitat selection, food supply and predation on recruitment of an estuarine fish. Oecologia 112:55-63

Lewis SM (1985) Herbivory on coral reefs: algal susceptibility to herbivorous fishes. Oecologia 65:370-375

Lotze HK, Lenihan HS, Bourque BJ, Bradbury RH, Cooke RG, Kay MC, Kidwell SM, Kirby MX, Peterson CH, Jackson JBC (2006) Depletion, degradation, and recovery potential of estuaries and coastal seas. Science 312:1806-1809

Madin EMP, Gaines SD, Warner RR (2010) Field evidence for pervasive indirect effects of fishing on prey foraging behaviour. Ecology (in press)

Meyer KD, Paul VJ, Sanger HR, Nelson SG (1994) Effects of seaweed extracts and secondary metabolites on feeding by the herbivorous surgeonfish Naso lituratus. Coral Reefs 13:105-112

Miller J, Maragos J, Brainard R, Asher J, Vargas-Ángel B, Kenyon J, Schroeder R, Richards B, Nadon M, Vroom P, Hall A, Keenan E, Timmers M, Gove J, Smith E, Weiss J, Lundblad E, Ferguson S, Lichowski F, Rooney J (2008) The state of coral reef ecosystems of the Pacific Remote Island Areas. In: Waddell JE, Clarke AM (eds) The state of coral reef ecosystems of the United States and Pacific Freely Associated States: 2008. NOAA Technical Memorandum NOS NCCOS 73. NOAA/NCCOS Center for Coastal Monitoring and Assessment's Biogeography Team, Silver Spring, pp 354-386

Mumby PJ (2009) Herbivory versus corallivory: are parrotfish good or bad for Caribbean coral reefs? Coral Reefs 28:683-690

Myers RA, Worm B (2005) Extinction, survival, or recovery of large predatory fishes. Proc R Soc Lond B Biol 360:13-20

Pace ML, Cole JJ, Carpenter SR, Kitchell JF (1999) Trophic cascades revealed in diverse ecosystems. Trends Ecol Evol 14:483-488

Paul VJ, Van Alstyne KL (1992) Activation of chemical defenses in the tropical green-algae Halimeda spp. J Exp Mar Biol Ecol 160:191-203

Pauly D, Christensen V, Dalsgaard J, Froese R, Torres F (1998) Fishing down marine food webs. Science 279:860-863

Preisser EL, Bolnick DI, Benard MF (2005) Scared to death? The effects of intimidation and consumption in predator-prey interactions. Ecology 86:501-509

Pringle RM, Young TP, Rubenstein DI, McCauley DJ (2007) Herbivore-initiated interaction cascades and their modulation by 
productivity in an African savanna. Proc Natl Acad Sci USA 104:193-197

R: A language and environment for statistical computing. R Foundation for Statistical Computing, Vienna, Austria. ISBN 3-900051-07-0. http://www.R-project.org

Samoilys MA, Carlos G (2000) Determining methods of underwater visual census for estimating the abundance of coral reef fishes. Environ Biol Fish 57:289-304

Sinclair ARE, Norton-Griffiths M (eds) (1995) Serengeti: dynamics of an ecosystem. University of Chicago Press, Chicago

Stallings CD (2008) Indirect effects of an exploited predator on recruitment of coral-reef fishes. Ecology 89:2090-2095

Steneck RS (1986) The ecology of coralline algal crusts: convergent patterns and adaptive strategies. Annu Rev Ecol Syst 17:273-303
Stevenson C, Katz LS, Micheli F, Block B, Heiman KW, Perle C, Weng K, Dunbar R, Witting J (2007) High apex predator biomass on remote pacific islands. Coral Reefs 26:47-51

Terborgh J, Estes JA (eds) (2010) Trophic cascades: predators, prey, and the changing dynamics of nature. Island Press, Washington, DC

Terborgh J, Lopez L, Nunez P, Rao M, Shahabuddin G, Orihuela G, Riveros M, Ascanio R, Adler GH, Lambert TD, Balbas L (2001) Ecological meltdown in predator-free forest fragments. Science 294:1923-1926

Venables WN, Ripley BD (2002) Modern applied statistics with S, 4th edn. Springer, New York

Werner EE, Gilliam JF, Hall DJ, Mittelbach GG (1983) An experimental test of the effects of predation risk on habitat use in fish. Ecology 64:1540-1548 